\title{
STRATEGI PENGEMBANGAN USAHA KECIL DAN MENENGAH DI KABUPATEN MANOKWARI
}

\author{
Jein Sriana Toyib', Anik Wuriasih ${ }^{2}$ Ted Matheus Suruan ${ }^{3}$
}

1,2,3Universitas Papua. E-mail:jeintoyib@gmail.com

\begin{tabular}{|c|c|}
\hline ARTICLE INFO & ABSTRACT \\
\hline $\begin{array}{l}\text { Keywords: } \\
\text { Growth strategy, market and product } \\
\text { development, and market penetration } \\
\text { How to cite: } \\
\text { Toyib, JS., Wuriasih, A., Suruan, TM., } \\
\text { (2018). Strategi Pengembangan Usaha Kecil } \\
\text { Dan Menengah Di Kabupaten Manokwari. } \\
\text { JMM UNRAM, 7(4), 101-112. } \\
\text { DOI : } \\
\text { 10.29303/jmm.v7i4.363 }\end{array}$ & $\begin{array}{l}\text { Development strategies for small and medium enterprises in } \\
\text { Manokwari Regency. } \\
\text { Globally, the economic actors should be able to strengthen } \\
\text { the capability during the ASEAN Economic Community } \\
\text { including small and medium business actors. Therefore, this } \\
\text { paper was intended to analyse and develop the strategies to } \\
\text { enhance the capacity of small and medium enterprises in } \\
\text { Manokwari Regency. The primary data concerning the } \\
\text { strengths, weaknesses, opportunities, and threats of } 50 \text { small } \\
\text { and medium enterprises were obtained systematically by } \\
\text { implementing questionnaires and direct interviews to apply } \\
\text { the SWOT analysis. The results revealed that the proper } \\
\text { strategies were the growth strategy, market and product } \\
\text { development, and market penetration. } \\
\text { Persaingan yang ketat antara pelaku ekonomi termaksud } \\
\text { pelaku usaha kecil dan menengah merupakan tantangan } \\
\text { yang harus dihadapi dalam era Masyarakat Ekonomi Asean. } \\
\text { Tujuan penelitian ini untuk menyusun strategi } \\
\text { pengembangan usaha kecil dan menengah di Kabupaten } \\
\text { Manokwari. Penelitian ini adalah penelitian kualitatif, } \\
\text { dengan metode penelitian deskriptif. Populasi penelitian } \\
\text { adalah seluruh usaha kecil menengah yang tercatat di Dinas } \\
\text { Koperasi dan UKM Kabupaten Manokwari. Sampel } \\
\text { penelitian berjumlah } 50 \text { UKM. Data dikumpulkan melalui } \\
\text { melalui penyebaran kuisoner dan wawancara langsung } \\
\text { terhadap usaha kecil dan menengah. Tehnik analisis data } \\
\text { dengan mengunakan analisis deskriptif dan analisis SWOT } \\
\text { untuk melihat strategi yang tepat bagi pengembangan usaha } \\
\text { kecil dan menengah di Kabupaten Manokwari. }\end{array}$ \\
\hline & Copyright ( 2018 JMM UNRAM. All rights reserved. \\
\hline
\end{tabular}




\section{Jurnal Magister Manajemen Unram Vol. 7, No 4. November 2018}

\section{NATIONALLY ACCREDITED JOURNAL - DECREE NO. 21/E/KPT/2018}

\section{PENDAHULUAN}

Globalisasi dan kemajuan teknologi dapat memberikan peluang sekaligus ancaman bagi perusahaan. Perubahan lingkungan dan sosial bisnis tidak dapat dihindari (Loucks dkk., 2010), untuk dapat terus melaksanakan kinerjanya perusahaan harus memiliki visi, misi dan strategi yang kuat. (Daygulu dkk., 2016). Perusahaan harus mengadopsi campuran orientasi strategis yang fleksibel dan beragam sesuai dengan kebutuhan dan kondisi eksternal di mana perusahaan beroperasi (Hosseininia dan Ramezani, 2016). Peran penting strategi dalam keberlangsungan organisasasi baik profit maupun non profit mampu mempengaruhi kinerja perusahaan dan mempertahankan kinerja serta keberlangsungan usahanya (Daygulu dkk., 2016) dan dapat menentukan arah dan posisi bersaing perusahaan (Hosseininia dan Ramezani, 2016).

Gambar 1. Perkembangan Unit Usaha dan jumlah tenaga kerja Usaha Mikro Kecil dan Menengah di Indonesia

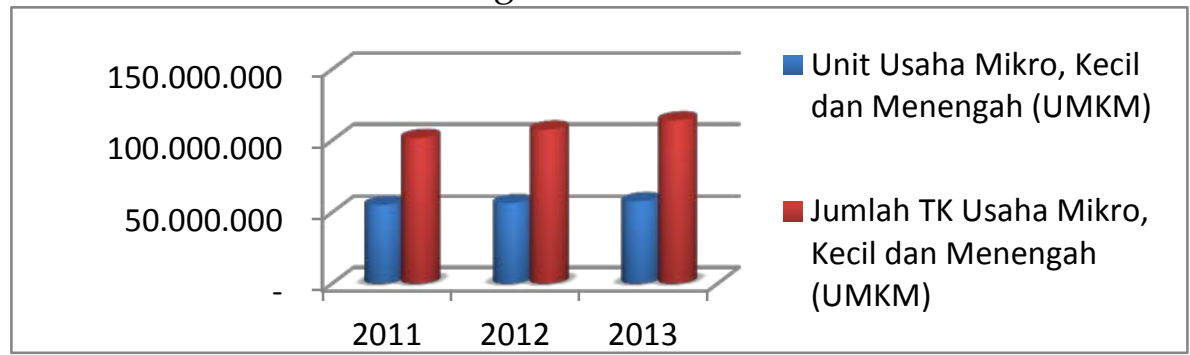

Sumber Data : Kementerian Koperasi dan UMKM, 2016

Usaha mikro kecil dan menengah (UMKM) menjadi salah satu faktor pengerak perkembangan ekonomi dan pendorong aliran perdagangan dan investasi suatu negara. UMKM tidak hanya berkontribusi pada pembangunan ekonomi suatu negara, namun UMKM juga dapat menjadi tolak ukur tingkat keberhasilan efektivitas kebijakan pemerintah dalam memelihara budaya kewirausahaan dalam suatu perekonomian. (Nasir dkk., 2016). Pada tahun 2016 Sektor UMKM telah memberikan kontribusi yang cukup besar terhadap produk domestik bruto Indonesia bertumbuh sebesar 60,34 dengan penyerapan tenaga kerja mencapai 97,22 persen. (Kemenperin, 2018). Unit usaha mikro kecil dan menengah di Indonesia juga terus mengalami perkembangan. Tabel 1 menunjukan bahwa pada tahun 2012 jumlah unit UMKM bertumbuh $2 \%$ dan pada tahun 2013 bertumbuh lagi $2 \%$. Selain itu penyerapan jumlah tenaga kerja UMKM di Indonesia juga mengalami peningkatan yang cukup signifikan, meningkat 5,8\% dan pada tahun 2013 penyerapan tenaga kerja oleh UMKM meningkat $6 \%$. Ini menunjukan bahwa UMKM tidak hanya berperan meningkatkan pertumbuhan ekonomi tetapi memiliki kontribusi yang besar dalam mengatasi masalah pengangguran (Thamrin dkk., 2017).

Potensi sumber daya alam yang ada di Provinsi Papua Barat dapat menjadi daya tarik bagi investor untuk berinvestasi dan mengembangkan usaha dengan memanfaatkan potensi yang tersedia. Jumlah usaha/perusahaan di Provinsi Papua Barat menurut data Sensus Ekonomi pada tahun 2016 mengalami kenaikan sebesar 60.57 persen dari satu dekade sebelumnya, selain itu perkembangan lapangan usaha berdasarkan skala usaha ditahun yang sama adalah sebesar 97,80 persen termaksud dalam skala Usaha Mikro Kecil (UMK) dan sisanya sebesar 2,20 adalah Skala Usaha Menengah Besar. Perkembangan ini hampir sama dengan pertumbuhan usaha di Kabupaten Manokwari yaitu skala Usaha Mikro Kecil (UMK) sebesar 97,80 persen dan Skala Usaha Menengah Besar sebesar 3 persen. 


\section{Jurnal Magister Manajemen Unram Vol. 7, No 4. November 2018}

\section{NATIONALLY ACCREDITED JOURNAL - DECREE NO. 21/E/KPT/2018}

Loucks dkk., (2010) menjelaskan bahwa setiap bisnis harus mengawasi apa yang terjadi di lingkungan internal dan eksternalnya, baik dalam jangka pendek maupun jangka panjang. Karena lingkungan terus berubah maka para manajer perlu menyesuaikan strategi baru terhadap perubahan itu (Helms dkk., 2011). Keputusan manajemen yang salah dapat menyebabkan konsekuensi ekonomi yang serius bagi perkembangan bisnis oleh karena itu dibutuhkan pengambilan strategi yang tepat (Tsitsipati dan Athanasios, 2013).

Demikian juga UMKM perlu mengadopsi strategi yang fleksibel dan beragam sesuai dengan kebutuhan dan kondisi eksternal di mana bisnis beroperasi (Hosseininia dan Ramezani, 2016; Kalpande dkk 2010). Agar berhasil di bidang apa pun, bisnis harus mampu mengolah kelemahan menjadi kekuatan dan ancaman harus ditransfer menjadi peluang. SWOT mengidentifikasi sejauh mana strategi organisasi melalui kekuatan dan kelemahan yang relevan dan mampu menangani perubahan yang terjadi di lingkungan bisnis. (Kalpande dkk., 2010; Thamrin dkk., 2017).

Perhatian terhadap perkembangan usaha mikro kecil dan menengah sangat diperlukan karena UMKM adalah sektor yang dapat mendukung pertumbuhan ekonomi daerah, menyerap tenaga kerja dan secara langsung mengerakan ekonomi masyarakat serta meningkatkan kesejahteraan masyarakat. Penelitian bertujuan memberikan informasi mengenai strategi pengembangan kinerja UKM di Kabupaten Manokwari dengan mengidentifikasi faktor internal dan eksternal UKM mengunakan analisis SWOT. Dengan mencantumkan isu-isu internal dan eksternal yang menguntungkan dan tidak menguntungkan di empat kuadran analisis SWOT, para perencana dapat lebih memahami bagaimana kekuatan dapat dimanfaatkan untuk merealisasikan peluang baru dan memahami bagaimana kelemahan dapat memperlambat kemajuan atau memperbesar ancaman (Helms dkk., 2011).

\section{LITERATURE REVIEW}

Persaingan yang kompetitif dikarenakan lingkungan yang terus berubah menjadikan manajemen lingkungan menjadi faktor kunci dari kesuksesan usaha (Hai, 2008). Jauch dan Glueck (1999) menjelaskan faktor-faktor yang mempengaruhi kinerja suatu usaha dapat dikelompokkan menjadi tiga faktor yaitu (1) faktor internal, (2) faktor eksternal, dan (3) faktor entrepreneurial skill. Faktor internal berada dalam kendali manajemen perusahaan (Shiamwama dkk., 2014) salah satunya adalah sumber daya yang dimiliki oleh perusahaan.

Barney dan Arikan (2001) menegaskan bahwa sumber daya adalah aset berwujud dan tidak berwujud yang dimiliki perusahaan yang berharga, langka, mahal untuk ditiru, dan tidak dapat disubstitusi. Teori berbasis sumber daya menjelaskan bagaimana sumber daya terhubung dengan strategi yang dijalankan oleh perusahaan. Sumber daya digunakan dalam menerapkan berbagai alternatif strategi yang diputuskan oleh perusahaan (Barney, 1996) yang dapat menciptakan keunggulan kompetitif perusahaan (Williams, 1992).

Teori keunggulan kompetitif memiliki hubungan yang erat dengan teori kreativitas dan kewirausahaan, menurut Barney dan Arikan, (2001) alternatif strategis yang digunakan perusahaan untuk mengeksploitasi sumber daya yang dimiliki perusahaan merupakan proses kreatif dan kewirausahaan. Keunggulan kompetitif merupakan strategi yang mengandung paling tidak satu dari dari hal berikut: efisiensi superior, kualitas unggul, inovasi superior, atau respons pelanggan yang superior, tingkat produktivitas dan kualitas produk (Hai, 2008; Vasilescu, 2008).

Untuk mecapai keunggulan yang dibutuhkan organisasi perlu mengembangkan kompetensi dari sumber daya dan kemampuan yang dimiliki perusahaan. (Hai, 2008). Keberhasilan 


\title{
Jurnal Magister Manajemen Unram ～Vol. 7, No 4. November 2018
}

\author{
NATIONALLY ACCREDITED JOURNAL - DECREE NO. 21/E/KPT/2018
}

pengusaha UKM ditentukan juga oleh infrastruktur, aspek sosial, lingkungan politik, akses ke pasar dan modal, teknologi (Chowdhury dkk., 2013; Hosseininia dan Ramezani, 2016; Indarti dan Langenberg, 2004; Vasilescu, 2008; Kalpande dkk., 2010). Penyederhanaan birokrasi dan deregulasi aspek hukum juga dianjurkan untuk mendorong perkembangan usaha UKM (Indarti dan Langenberg, 2004; Vasilescu, 2008).

Abosede dkk., 2016 menjelaskan adanya hubungan antara manajemen strategis dan pengembangan UKM di negara-negara maju dan negara-negara berkembang. Perusahaan dengan strategi yang jelas dan konsisten akan mengungguli mereka yang tidak memiliki strategi formal dan komprehensif. Pengelolaan mengenai informasi pasar, kepemilikan, pilihan strategi, keunggulan kompetitif, perencanaan, dan inovasi memiliki pengaruh penting pada pengembangan UKM. (Hosseininia dan Ramezani, 2016; Abosede dkk., 2016).

Glaister dan Falshaw (1999) menjelaskan Analisis SWOT adalah salah satu alat perencanaan strategis yang paling umum digunakan yang menganalisis kekuatan, kelemahan, peluang, dan ancaman pada sebuah bisnis. Helms dkk., (2011) menegaskan SWOT digunakan untuk mengidentifikasi hambatan dan kelebihan dari berbagai faktor eksternal dan internal perusahaan serta memanfaatkan peluang dalam berbagai macam situasi bisnis. Analisis SWOT adalah kombinasi dari kekuatan, peluang, kelemahan dan ancaman dan merupakan salah satu teknik untuk melakukan analisis struktural faktor internal dan ekseternal perusahaan dan merumuskannya menjadi strategi terbaik (Hai, 2008; Thamrin dkk., 2017; Kalpande dkk., 2010).

Selanjutnya Kalpande dkk., 2010 menjelaskan tujuan dari analisis SWOT adalah untuk mengidentifikasi sejauh mana strategi organisasi saat ini menentukan kekuatan dan kelemahan yang relevan serta bagaiman menangani perubahan yang terjadi di lingkungan bisnis. Analisis SWOT juga membantu dalam mengidentifikasi internalitas dan eksternalitas yang berinteraksi dengan lingkungan bisnis yang lebih luas, sehingga pembuat kebijakan dapat membuat perubahan terhadap proses berwirausaha yang lebih mudah dan mendorong pertumbuhan kewirausahaan (Helms dkk., 2011).

\section{METODE ANALISIS}

Pendekatan analisis data yang digunakan dalam penelitian ini adalah pendekatan kualitatif untuk memahami dan memaknai apa yang terjadi pada individu dalam masyarakat ataupun objek lain dengan mengamati perilaku, persepsi, tindakan secara holistic yang disajikan dalam bentuk katakata dan bahasa dengan menggunakan berbagai metode ilmiah yang dijelaskan secara deskriptif. Data berasal dari hasil wawancara beberapa UMKM potensial yang ada di Kabupaten Manokwari. Perumusan strategi dimulai pada tahap input yaitu meringkas informasi input dasar yang diperlukan untuk merumuskan strategi. Tahap kedua adalah tahap pencocokan yaitu menghasilkan strategi alternatif dengan memadukan faktor-faktor eksternal dan internal. Tahap ketiga yaitu tahap keputusan yang akan menentukan strategi alternatif mana yang paling sesuai untuk digunakan. Penelitian ini diawali dengan melakukan analisis lingkungan internal dan eksternal usaha kecil menengah menggunakan metode deskriptif. Dilanjutkan pada tahap input yaitu melakukan pembobotan dan perangkingan pada setiap faktor kunci. Kemudian memasukkan hasil yang telah dibobotkan dan dirangkingkan dari analisis lingkungan internal sebagai informasi untuk mengidentifikasi kekuatan dan kelemahan yang menghasilkan matriks IFE, sedangkan hasil dari analisis lingkungan eksternal sebagai informasi untuk mengidentifikasi peluang dan ancaman yang menghasilkan matriks EFE. Tahap berikutnya dilanjutkan pada tahap pencocokan yaitu menyusun alternatif strategi berdasarkan peluang, ancaman, kekuatan, dan kelemahan yang telah 


\section{Jurnal Magister Manajemen Unram Vol. 7, No 4. November 2018}

\section{NATIONALLY ACCREDITED JOURNAL - DECREE NO. 21/E/KPT/2018}

diidentifikasi dengan menggunakan matriks IE dan analisis SWOT. Tahap terakhir adalah memprioritaskan alternatif strategi yang dihasilkan pada analisis SWOT.

\section{HASIL DAN PEMBAHASAN}

Responden dalam penelitian adalah pelaku UMKM yang ada di Kabupaten Manokwari Distrik Manokwari Barat. Sampel penelitian berjumlah 50 UKM yang diambil dengan teknik purposive sampling. Dari hasil diskusi pada saat wawancara tergambarkan bahwa usaha UMKM Kabupaten Manokwari memiliki potensi yang cukup besar. Potensi pengembangan usaha sektor UMKM di Kabupaten Manokwari didukung oleh ketersediaan sumber daya alam yang dimiliki dan telah memberikan kontribusi yang signifikan terhadap perekonomian masyarakat di Kabupaten Manokwari. Namun tidak dapat dipungkiri bahwa keberadaan UMKM di Kabupaten Manokwari masih lemah dalam berbagai aspek usaha, utamanya kemampuan SDM, sarana dan prasarana, permodalan maupun dari segi pemasarannya produk.

\subsection{Identifikasi UMKM di Kabupaten Manokwari}

Tahapan identifikasi dan deskripsi usaha UMKM di Kabupaten Manokwari dilakukan pada 9 (sembilan) aspek. Kesembilan aspek dimaksud yaitu (1) aspek pemasaran; (2) aspek modal dan pendanaan usaha; (3)aspek pemanfaatan teknologi dan informasi; (4) aspek pemakaian bahan baku; (5) aspek peralatan produksi; (6) aspek penyerapan dan pembardayaan tenaga kerja; (7) aspek organisasi dan manajemen usaha; (8)aspek birokrasi dan peran pemerintah; dan (9) aspek eksternalitas dan lain-lain.

\subsection{Faktor Internal dan Eksternal yang Mempengaruhi Perkembangan UMKM di Kabupaten Manokwari}

Identifikasi faktor internal dan faktor eksternal yang mempengaruhi perkembangan UMKM dilakukan guna menentukan strategi pengembangan UMKM di Kabupaten Manokwari kedepan. Proses identifikasi faktor-faktor tersebut dilakukan dengan analisis SWOT. Analisis SWOT menurut Helms dkk., 2011 digunakan untuk mengidentivikasi berbagai faktor secara sistematis dan efektif, dan berfungsi untuk mengidentivikasi dan mengevaluasi kekuatan, kelemahan, peluang, dan ancaman dan memanfaatkannya untuk perumusan strategis.

Proses identifikasi ini menghasilkan faktor internal dan eksternal yang menjadikan UMKM di Kabupaten Manokwari berpotensi untuk dikembangkan, dengan berbagai persoalan yang dihadapi. Selanjutnya faktor internal diuraikan untuk menganalisis kekuatan dan kelemahan, sedangkan faktor eksternal digunakan untuk menganalisis peluang dan ancaman sektor UMKM di Kabupaten Manokwari.

Adapun faktor internal yang teridentifikasi dan menjadi kekuatan strategi pengembangan sektor UMKM di Kabupaten Manokwari, yaitu:(1) lokasi UMKM yang strategis; (2) harga produk yang mampu bersaing dengan produk sejenis; (3) bahan baku mudah diperoleh; dan (4) ketersedian tenaga kerja yang memadai. Selain sebagai kekuatan strategi UMKM, proses identifikasi juga dilakukan terhadap faktor internal yang menjadi kelemahan UMKM di Kabupaten Manokwari, yaitu: (1) keterbatasan modal usaha; (2) pemahaman pelaku UMKM tentang manajemen usaha, sistem, dan proses pemasaran relatif lemah; (3) Masih kurangnya informasi sumber pembiayaan dan pengalaman dalam pengajuan pembiayaan pada Bank maupun lembaga keuangan; dan (4) peralatan produksi yang masih sederhana. 


\section{NATIONALLY ACCREDITED JOURNAL - DECREE NO. 21/E/KPT/2018}

Selanjutnya, hasil identifikasi terhadap faktor eksternal yang menjadi peluang pengembangan sektor UMKM di Kabupaten Manokwari, meliputi: (1) terbuka peluang pasar untuk domestik dan antar pulau; (2) kecenderungan masyarakat menggunakan produk lokal; (3) dukungan Pemerintah meningkatkan potensi UMKM; dan (4) ketersediaan infrastruktur pendukung. Sedangkan yang menjadi ancaman pengembangan sektor UMKM di Kabupaten Manokwari, yaitu: (1) Kondisi perekonomian secara umum dirasakan berat dan mempengaruhi perkembangan usaha; (2) tingkat inflasi yang tinggi; (3) Kurang dapat beradaptasi dengan perkembangan teknologi dan informasi; dan (4) Adanya tingkat gangguan keamanan pada usaha yang tinggi (pencurian, penipuan, kriminal dll).

Tabel 1. Faktor Internal dan Eksternal Sektor UMKM di Kabupaten Manokwari

\begin{tabular}{lll}
\hline No Kekuatan (strengths) & Kelemahan (weaknesses) \\
\hline 1. Lokasi usaha yang strategis; & 1. Keterbatasan modal usaha; \\
2. Harga produk yang mampu & 2. Pemahaman dari pelaku UMKM \\
bersaing dari produk-produk & tentang manajemen usaha, strategi, \\
sejenis; & sistem dan proses pemasaran relatif \\
3. Bahan baku mudah diperoleh & lemah; \\
dengan harga bahan baku murah & 3. Masih kurangnya informasi sumber \\
dan kualitas; & pembiayaan dan pengalaman dalam \\
4. Ketersediaan tenaga kerja yang & pengajuan pembiayaan pada Bank \\
memadai & maupun lembaga keuangan;; \\
& 4. Peralatan produksi yang masih \\
& sederhana
\end{tabular}

\begin{tabular}{|c|c|c|}
\hline No & Peluang (opportunities) & Ancaman (threats) \\
\hline & $\begin{array}{l}\text { 1. Terbuka peluang pasar untuk } \\
\text { domestik dan ekspor antar } \\
\text { pulau; }\end{array}$ & $\begin{array}{l}\text { 1. Kondisi perekonomian secara umum } \\
\text { dirasakan berat dan mempengaruhi } \\
\text { perkembangan usaha; }\end{array}$ \\
\hline & $\begin{array}{l}\text { 2. Kecenderungan masyarakat yang } \\
\text { cukup besar terhadap produk }\end{array}$ & $\begin{array}{l}\text { 2. Tingkat Inflasi yang selalu meningkat } \\
\text { dari tahun ke tahun; }\end{array}$ \\
\hline & lokal; & 3. Kurang dapat beradaptasi dengan \\
\hline & $\begin{array}{l}\text { 3. Dukungan program pemerintah } \\
\text { dalam peningkatan potensi }\end{array}$ & $\begin{array}{l}\text { perkembangan teknologi dan } \\
\text { informasi; }\end{array}$ \\
\hline & UMKM di Kabupaten & 4. Adanya tingkat gangguan keamanan \\
\hline & Manokwari; & pada usaha yang tinggi (pencurian, \\
\hline & $\begin{array}{l}\text { 4. Ketersedian infrastruktur } \\
\text { pendukung }\end{array}$ & penipuan, kriminal dll) \\
\hline
\end{tabular}

Sumber: Data primer diolah, 2018

4.3. Matriks Internal Strategic Factors Analysis Summary (IFAS) dan External Strategic Factors Analysis Summary (EFAS)

Analisis pada tahapan selanjutnya yaitu melakukan proses matrik strategi faktor internal (internal strategic factors analysis/IFAS) dan matriks strategi faktor eksternal (external strategic factors analysis/EFAS). Tujuannya yaitu untuk melihat posisi tiap faktor yang termasuk dalam kekuatan, kelemahan, peluang, dan ancaman pengembangan sektor UMKM di Kabupaten Manokwari. 


\section{Jurnal Magister Manajemen Unram}

\section{NATIONALLY ACCREDITED JOURNAL - DECREE NO. 21/E/KPT/2018}

Tabel 15 menunjukkan bahwa urutan nilai tertinggi sampai terendah untuk faktor yang menjadi kekuatan adalah lokasi usaha yang strategis $(0,68)$, ketersediaan tenaga kerja yang memadai $(0,68)$, bahan baku mudah diperoleh dengan harga bahan baku murah dan kualitas $(0,64)$ serta Harga produk yang mampu bersaing dari produk-produk sejenis $(0,39)$. Berdasarkan urutan nilai tersebut, maka dapat dikatakan bahwa faktor unggulan UMKM di Manokwari adalah lokasi usaha yang strategis, tenaga kerja yang memadai serta ketersediaan bahan baku yang murah dan kualitas.

Sementara urutan nilai tertinggi sampai dengan terendah untuk faktor yang menjadi kelemahan pengembangan sektor UMKM di Kabupaten Manokwari, yaitu keterbatasan modal pengembangan usaha $(0,68)$, peralatan produksi masih sederhana $(0,27)$, masih kurangnya informasi sumber pembiayaan dan pengalaman dalam pengajuan pembiayaan pada Bank maupun lembaga keuangan $(0,12)$ dan pemahaman pelaku UMKM tentang manajemen usaha $(0,10)$. Urutan nilai tertinggi mengindikasikan bahwa faktor tersebut merupakan kekurangan UMKM dalam keberlangsungan usaha kedepannya.

Tabel 16. menunjukkan bahwa urutan nilai tertinggi sampai terendah untuk faktor yang menjadi peluang adalah kecenderungan masyarakat mengkonsumsi produk lokal $(0,81)$, kemudian ketersediaan infrastruktur pendukung $(0,45)$, dukungan dari pemerintah $(0,33)$, serta terbuka peluang pasar domestik dan antar pulau $(0,17)$. Berdasarkan urutan nilai tersebut, maka dapat dikatakan bahwa kecenderungan pola masyarakat akan produk lokal merupakan peluang utama pengembangan sektor UMKM di Kabupaten Manokwari selain infrastruktur dan dukungan pemerintah.

Sementara urutan nilai tertinggi sampai dengan terendah untuk faktor yang menjadi ancaman pengembangan sektor UMKM di Kabupaten Manokwari, yaitu kondisi perekonomian secara umum dirasakan berat dan mempengaruhi perkembangan usaha $(0,76)$, tingkat Inflasi yang selalu meningkat dari tahun ke tahun $(0,33)$, adanya tingkat gangguan keamanan pada usaha yang tinggi (pencurian, penipuan, kriminal dll) $(0,20)$, kurang dapat beradaptasi dengan perkembangan teknologi dan informasi $(0,10)$. Urutan nilai tertinggi mengindikasikan bahwa faktor tersebut merupakan ancaman serius bagi keberlangsungan usaha sektor UMKM kedepannya.

\section{Tabel 2. Matriks IFAS}

\begin{tabular}{|c|c|c|c|c|}
\hline No & Faktor Internal & $\begin{array}{l}\text { Bobot } \\
\text { (a) }\end{array}$ & $\begin{array}{c}\text { Rating } \\
\text { (b) }\end{array}$ & $\begin{array}{l}\text { Nilai } \\
(\mathrm{a} \times \mathrm{b})\end{array}$ \\
\hline \multirow[t]{5}{*}{1} & Kekuatan (+) & & & \\
\hline & 1. Lokasi usaha yang strategis & 0,17 & 4 & 0,68 \\
\hline & $\begin{array}{l}\text { 2. Harga produk yang mampu bersaing dari produk-produk } \\
\text { sejenis }\end{array}$ & 0,13 & 3 & 0,39 \\
\hline & $\begin{array}{l}\text { 3. Bahan baku mudah diperoleh dengan harga bahan baku } \\
\text { murah dan kualitas }\end{array}$ & 0,16 & 4 & 0,64 \\
\hline & 4. Ketersediaan tenaga kerja yang memadai & 0,17 & 4 & 0,68 \\
\hline \multirow[t]{4}{*}{2} & Kelemahan (-) & & & \\
\hline & 1. Keterbatasan modal usaha & 0,17 & 4 & 0,68 \\
\hline & $\begin{array}{l}\text { 2. Pemahaman dari pelaku UMKM tentang manajemen usaha, } \\
\text { strategi, sistem dan proses pemasaran relatif lemah }\end{array}$ & 0,05 & 2 & 0,10 \\
\hline & 3. Masih kurangnya informasi sumber pembiayaan dan & & 2 & \\
\hline
\end{tabular}


pengalaman dalam pengajuan pembiayaan pada Bank

maupun lembaga keuangan

4. Peralatan produksi sederhana
0,06

$\begin{array}{lll}0,09 & 3 & 0,27 \\ 1.00 & 3.56\end{array}$

Tabel 3. Matriks EFAS

\begin{tabular}{|c|c|c|c|c|}
\hline No & Faktor Eksternal & $\begin{array}{l}\text { Bobot } \\
\text { (a) }\end{array}$ & $\begin{array}{l}\text { Rating } \\
\text { (b) }\end{array}$ & $\begin{array}{l}\text { Nilai } \\
(\mathrm{a} \times \mathrm{b})\end{array}$ \\
\hline \multirow[t]{5}{*}{1} & Peluang (+) & & & \\
\hline & $\begin{array}{l}\text { 1. Terbuka peluang pasar untuk domestik dan ekspor antar } \\
\text { pulau }\end{array}$ & 0,09 & 2 & 0,17 \\
\hline & $\begin{array}{l}\text { 2. Kecenderungan konsumsi masyarakat yang cukup besar } \\
\text { terhadap hasil lokal. }\end{array}$ & 0,20 & 4 & 0,81 \\
\hline & $\begin{array}{l}\text { 3. Dukungan program pemerintah dalam peningkatan } \\
\text { potensi UMKM di Kabupaten Manokwari }\end{array}$ & 0,11 & 3 & 0,33 \\
\hline & 4. Ketersedian infrastruktur pendukung & 0,15 & 3 & 0,45 \\
\hline \multirow[t]{6}{*}{2} & Ancaman (-) & & & \\
\hline & $\begin{array}{l}\text { 1. Kondisi perekonomian secara umum dirasakan berat dan } \\
\text { mempengaruhi perkembangan usaha }\end{array}$ & 0,19 & 4 & 0,76 \\
\hline & 2. Tingkat Inflasi yang selalu meningkat dari tahun ke tahun & 0,11 & 3 & 0,33 \\
\hline & $\begin{array}{l}\text { 3. Kurang dapat beradaptasi dengan perkembangan } \\
\text { teknologi dan informasi }\end{array}$ & 0,05 & 2 & 0,10 \\
\hline & $\begin{array}{l}\text { 4. Adanya tingkat gangguan keamanan pada usaha yang } \\
\text { tinggi (pencurian, penipuan, kriminal dll) }\end{array}$ & 0,10 & 2 & 0,20 \\
\hline & Jumlah & 1.00 & & 3,15 \\
\hline
\end{tabular}

\subsection{Analisis Matriks Internal dan Eksternal}

Matriks I-E (Internal-Eksternal) diperoleh melalui penggabungan informasi dari tabel IFAS dan EFAS yang kemudian akan digunakan menentukan alternatif strategi. Nilai matriks IFAS sebesar 3,56 yang merupakan penjumlahan dari nilai faktor kekuatan $(2,39)$ dengan faktor kelemahan (1,17). Besaran nilai IFAS menunjukkan bahwa sektor UMKM di Kabupaten Manokwari dapat memanfaatkan unsur kekuatan yang dimiliki untuk mengatasi kelemahan internal UMKM yang ada. Selanjutnya, nilai yang diperoleh dari matrik EFAS sebesar 3.15 dan merupakan kombinasi penjumlahan dari faktor peluang $(1,77)$ dengan faktor ancaman $(1,38)$, mengindikasikan bahwa sektor UMKM di Kabupaten Manokwari memiliki kemampuan yang tinggi dalam memanfaatkan peluang dan menghindari ancaman yang ada.

Selanjutnya, nilai IFAS dan nilai EFAS dapat digunakan untuk menentukan posisi persaingan sektor UMKM di Kabupaten yaitu berada pada kuadran I. Pada posisi tersebut, pilihan strategi terbaik yang dapat dilakukan sektor UMKM di Kabupaten Manokwari yaitu strategi pertumbuhan, pengembangan pasar dan produk sektor UMKM, serta penetrasi pasar yang harus dilakukan secara intensif. Posisi sektor UMKM di Kabupaten Manokwari dapata dilhat pada Gambar 1. 


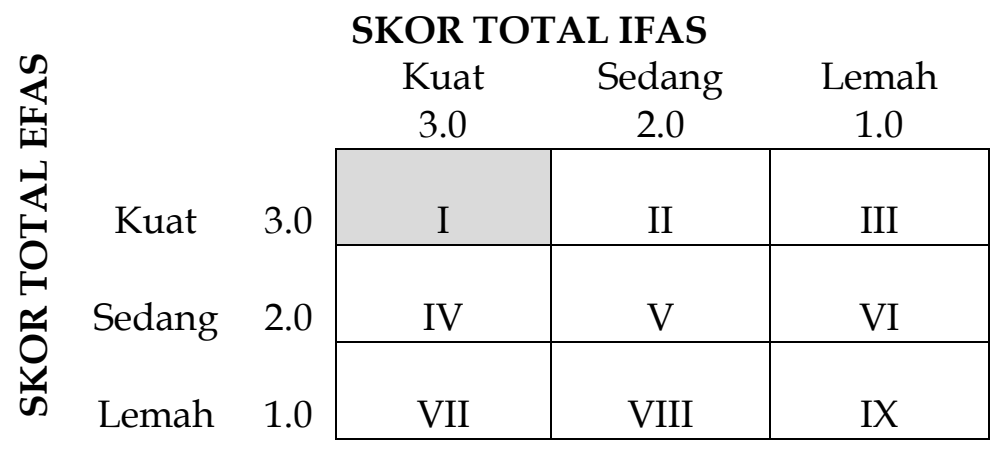

Gambar 1. Matrik IFAS-EFAS UMKM di Kabupaten Manokwari

\section{Matriks Analisis SWOT}

\begin{tabular}{|c|c|c|}
\hline Faktor Interna & $\begin{array}{l}\text { Kekuatan (S) } \\
\text { 1. Lokasi usaha yang strategis } \\
\text { 2. Harga produk yang mampu } \\
\text { bersaing dari produk sejenis } \\
\text { 3. Bahan baku mudah } \\
\text { diperoleh dengan harga } \\
\text { bahan baku murah dan } \\
\text { kualitas } \\
\text { 4. Ketersediaan tenaga kerja } \\
\text { yang memadai }\end{array}$ & $\begin{array}{l}\text { Kelemahan }(W) \\
\text { 1. Keterbatasan modal usaha } \\
\text { 2. Pemahaman dari pelaku } \\
\text { UMKM tentang manajemen } \\
\text { usaha, strategi, sistem dan } \\
\text { proses pemasaran relatif } \\
\text { lemah } \\
\text { 3. Masih kurangnya informasi } \\
\text { sumber pembiayaan dan } \\
\text { pengalaman dalam pengajuan } \\
\text { pembiayaan pada Bank } \\
\text { maupun lembaga keuangan } \\
\text { 4. Peralatan produksi sederhana }\end{array}$ \\
\hline Peluang (O) & Strate & Strategi (W-O) \\
\hline $\begin{array}{l}\text { 1. Terbuka peluang pasar } \\
\text { untuk domestik dan } \\
\text { ekspor. } \\
\text { 2. Kecenderungan } \\
\text { konsumsi masvarakat }\end{array}$ & $\begin{array}{l}\text { 1. Meningkatkan potensi } \\
\text { usaha dengan } \\
\text { memanfaatkan lokasi yang } \\
\text { strategis dan kemudahan }\end{array}$ & $\begin{array}{l}\text { 1. Dukungan pemerintah dalam } \\
\text { bentuk bantuan dana dan } \\
\text { program, dapat digunakan } \\
\text { untuk mengatasi keterbatasan }\end{array}$ \\
\hline $\begin{array}{l}\text { yang cukup besar } \\
\text { terhadap hasil lokal. } \\
\text { 3. Dukungan program } \\
\text { pemerintah dalam } \\
\text { peningkatan potensi }\end{array}$ & $\begin{array}{l}\text { 2. Dukungan pemerintah } \\
\text { dapat dimanfaatkan untuk } \\
\text { meningkatkan produksi dan } \\
\text { perkembangan akses } \\
\text { informasi; }\end{array}$ & $\begin{array}{l}\text { 2. Memanfaatkan penggunaan } \\
\text { media cetak dan media } \\
\text { elektronik untuk } \\
\text { mempromosikan produk ke } \\
\text { masyarakat umum; }\end{array}$ \\
\hline $\begin{array}{l}\text { UMKM di Kabupaten } \\
\text { Manokwari. } \\
\text { 4. Ketersedian } \\
\text { infrastruktur }\end{array}$ & $\begin{array}{l}\text { 3. Meningkatkan kualitas } \\
\text { tenaga kerja yang sudah } \\
\text { ada guna meningkatkan } \\
\text { volume dan kualitas }\end{array}$ & $\begin{array}{l}\text { 3. Melakukan inovasi dan } \\
\text { variasi produk untuk menarik } \\
\text { dan menjaga loyalitas } \\
\text { pelanggang yang sudah ada. }\end{array}$ \\
\hline
\end{tabular}

\begin{tabular}{lll}
\hline Ancaman $(\mathrm{T})$ & Strategi (S-T) & Strategi $(\mathbf{W}-\mathrm{T})$ \\
1. Kondisi perekonomian & 1. Memanfaatkan lokasi yang & 1. Memperbaiki kualitas sistem \\
\hline
\end{tabular}


secara umum dirasakan

berat dan mempengaruhi

perkembangan usaha

2. Tingkat Inflasi yang selalu meningkat dari tahun ke tahun

3. Kurang dapat beradaptasi dengan perkembangan teknologi dan informasi;

4. Adanya tingkat gangguan keamanan pada usaha yang tinggi (pencurian, penipuan, kriminal dll) strategis dan menawarkan

promo khusus bagi

pelanggan untuk menarik

pelanggan baru;

2. Melakukan inovasi terhadap peralatan dan produksi yang ada.

3. Melakukan pendekatan melalui keterlibatan UKM pada pada programprogram keamanan di lingkungan usaha. manajemen usaha agar

mudah mendapatkan

bantuan modal usaha dari

bank dan lembaga keungan;

2. Mengunakan kondisi perekonomian dan keadaan lingkungan menjadi salah satu dasar perencanaan bagi perkembangan UMKM.

3. Memulai untuk beradaptasi dengan perkembangan informasi dan teknologi.

Hasil analisis menunjukkan bahwa kekuatan sektor UMKM di Kabupaten Manokwari yaitu umumnya memiliki lokasi usaha strategis, bahan baku mudah diperoleh dengan harga yang terjangkau, harga produk UMKM mampu bersaing dengan harga produk impor sejenis, dan memiliki tenaga kerja yang memadai. Selain kekuatan, kelemahan sektor UMKM di Kabupaten Manokwari meliputi keterbatasan modal pengembangan usaha, pemahaman tentang manajemen usaha, strategi sistem, dan proses pemasaran masih lemah, serta desain produk yang dihasilkan relatif sederhana.

Adapun faktor yang menjadi peluang sektor UMKM di Kabupaten Manokwari yaitu produk sektor UMKM memiliki peluang pasar lokal dan antar pulau, minat masyarakat yang tinggi terhadap produk lokal, serta dukungan Pemerintah dan infrastruktur pendukung yang sudah mulai berpihak. Selanjutnya, ancaman yang menjadi kendala sektor UMKM meliputi tingginya inflasi, rendahnya perlingdungan usaha dari monopoli pasar maupun dari pemerintah, kesulitan memperoleh bantuan pembiayaan pengembangan usaha dengan bunga lunak, dan tingkat gangguan keamanan pada usaha yang cukup tinggi (pencurian, penipuan, kriminal dll).

\section{KESIMPULAN}

Berdasarkan analisis matriks internal (kekuatan dan kelemahan) dan eksternal (peluang dan ancaman), posisi persaingan sektor UMKM di Kabupaten yaitu berada pada kuadran I. Pada posisi tersebut, pilihan strategi terbaik yang dapat dilakukan yaitu strategi pertumbuhan, pengembangan pasar dan produk, serta penetrasi pasar. Oleh karenanya, rumusan strategi pengembangan yang dapat dilakukan oleh sector UMKM di Kabupaten Manokwari yaitu memanfaatkan lokasi UMKM yang strategis dan memanfaatkan dukungan pemerintah untuk meningkatkan produksi dan meningkatkan kualitas tenaga kerja serta memanfaatkan perkembangan teknologi dan informasi, sehingga dapat meningkatkan volume dan kualitas produksi. Dukungan pemerintah dalam bentuk bantuan dana dan program dimanfaatkan untuk mengatasi keterbatasan modal usaha. UMKM juga dapat memanfaatkan media untuk mempromosikan produk ke masyarakat umum, melakukan inovasi dan variasi produk, dan melakukan efisiensi dalam penggunaan peralatan produksi yang ada serta, memperbaiki kualitas sistem manajemen usaha. 


\title{
Jurnal Magister Manajemen Unram ～Vol. 7, No 4. November 2018
}

\author{
NATIONALLY ACCREDITED JOURNAL - DECREE NO. 21/E/KPT/2018
}

\section{SARAN}

Adapun saran yang dapat diberikan adalah :

1. Perlunya dukungan terhadap pengembangan UKM melalui strategi yang tepat untuk mempersiapkan dan mendorong UKM agar usaha kecil dan menengah di Kabupaten Manokwari dapat tetap bertumbuh, bertahan dan survive menghadapi persaingan bisnis saat ini.

2. Perlu adanya kajian komperhensif mengenai strategi yang tepat untuk menangani UKM di Kabupaten Manokwari sehingga kebijakan yang dilahirkan berpihak kepada pelaku UKM dan berdampak pada kemampuan UKM terlibat dalam persaingan lingkungan bisnis saat ini.

\section{ACKNOWLEDGEMENTS}

Terimakasih yang tulus bagi setiap pihak yang telah membantu terlaksananya penelitian ini, bagi petugas lapangan (observer dan interviwer), bagi partisipan pelaku UKM yang telah memberikan waktunya untuk berdiskusi dan berbagi pengalaman, dan secara khusus bagi Dirjen DIKTI atas pendanaan yang telah diberika sehingga penelitian ini dapat terlaksana.

\section{REFERENCES}

Barney, J. B. (1996). The resource-based theory of the firm. Organization Science, 7(5), 469. https://doi.org/10.1287/orsc.7.5.469

Barney, J. B., \& Arikan, A. M. (2001). The resource-based view: origins and implications. The Blackwell Handbook of Strategic Management, 124-188. https:/ / doi.org/10.1177/014920639101700107

Chowdhury, M. ;, Alam, Z. ;, \& Arif, M. I. ; (2013). Success Factors of Entrepreneurs of Small and Medium Sized Enterprises: Evidence from Bangladesh. Business $\mathcal{E}$ Economic Research. https:/ / doi.org/10.5296/ ber.v3i2.4127

Duygulu, E., Ozeren, E., Iş1ldar, P., \& Appolloni, A. (2016). The Sustainable Strategy for Small and Medium Sized Enterprises: The Relationship between Mission Statements and Performance. Sustainability, 8(7), 698. https:// doi.org/10.3390/su8070698

Glaister, K. W., \& Richard Falshaw, J. (1999). Strategic planning: Still going strong? Long Range Planning, 32(1), 107-116. https://doi.org/10.1016/S0024-6301(98)00131-9

Hai, H. (2008). Assessing the SMEs' competitive strategies on the impact of environmental factors: A quantitative SWOT analysis application. WSEAS Transactions on Information Science and Applications, 5(12), 1701-1710.

Helms, M. M., Rodrí Guez, M. A., Ríos, L. D. L., \& Hargrave, W. B. (2011). Entrepreneurial potential in Argentina: A SWOT analysis. Competitiveness Review, 21(3), 269-287. https://doi.org/10.1108/10595421111134859

Hosseininia, G., \& Ramezani, A. (2016). Factors Influencing Sustainable Entrepreneurship in Small and Medium-Sized Enterprises in Iran: A Case Study of Food Industry. Sustainability, 8(10), 1010. https:/ / doi.org/10.3390/su8101010

Indarti, N., \& Langenberg, M. (2004). Factors affecting business success among SMEs: empirical evidences from Indonesia. Second Bi-Annual European Summer ..., (August), 1-15. Retrieved from http:/ / www.utwente.nl/mb/nikos/archief/esu2004/papers/indartilangenberg.pdf

Julius, A. A., Agbolade, O. K., \& Johnson, O. (2016). Strategic Management and Small and Medium Enterprises (SMEs) Development: A Review of Literature. International Review of Management 
NATIONALLY ACCREDITED JOURNAL - DECREE NO. 21/E/KPT/2018

and Business Research, 5(1), 315-335. Retrieved from http:/ / search.proquest.com.lopes.idm.oclc.org/central/docview/1798983931/fulltextPDF/84 007D208A9C433EPQ/102?accountid=7374

Kalpande, S. D., \& Gupta, R. C. (2010). A SWOT analysis of small and medium scale enterprises implementing total quality management. MultiCraft International Journal of Business, Management and Social Sciences, 1(1), 59-64. https:/ / doi.org/10.1177/ijbmss/355713513555

Loucks, E. S., Martens, M. L., \& Cho, C. H. (2010). Engaging small- and medium-sized businesses in sustainability. Sustainability Accounting, Management and Policy Journal, 1(2), 178-200. https:/ / doi.org/10.1108/20408021011089239

Nasir, W. M. N. bin W. M., Al Mamun, A., \& Breen, J. (2017). Strategic Orientation and Performance of SMEs in Malaysia. SAGE Open, 7(2), 1-13. https:/ / doi.org/10.1177/2158244017712768

Shiamwama, S. M., Ombayo, J. A., \& Mukolwe, M. S. (2014). Internal Factors Affecting the Performance of Businesses of Retirees in Kakamega Municipality. International Journal of Business, Humanities and Technology, 4(2), 144-157.

Tambunan, T. (2008). SME development, economic growth, and government intervention in a developing country: The Indonesian story. Journal of International Entrepreneurship, 6(4), 147167. https:/ / doi.org/10.1007/s10843-008-0025-7

Thamrin, H., Herlambang, R., Brylian, B., Gumawang, A. K. A., \& Makmum, A. (2017). A SWOT analysis tool for Indonesian small and medium enterprise. ARPN Journal of Engineering and Applied Sciences, 12(2), 620-625.

Tsitsipati, V., \& Athanasios, C. (2014). Swot analysis of the truffles market in greece. British Food Journal, 116(12), 1976-1997. https:/ / doi.org/10.1108/BFJ-12-2012-0293

Vasilescu, L. G. (2008). a Swot Analysis of Smes ' Development in Romania. Journal of Applied Economic Sciences, III(4), 396-405. Retrieved from https://core.ac.uk/download/pdf/6768292.pdf

Williams, J. R. (1994). 'How sustainable is your competitive advantage?'. IEEE Engineering Management Review, 22(2), 84-94. 